\title{
Commentary
}

\section{Healthcare Reform in the U.S. Must Be Driven by Policy and Data, Not Politics and Ideology}

\author{
Teresa Waters ${ }^{1,}$, , Michael Karpf ${ }^{2}$ \\ ${ }^{1}$ Department of Health Management \& Policy, University of Kentucky College of Public Health, Lexington, Kentucky, United States \\ ${ }^{2}$ Department of Medicine, University of Kentucky College of Medicine, Lexington, Kentucky, United States
}

Email address:

teresa.waters@uky.edu (T. Waters),mkarpf@uky.edu (M. Karpf)

${ }^{*}$ Corresponding author

\section{To cite this article:}

Teresa Waters, Michael Karpf. Healthcare Reform in the U.S. Must Be Driven by Policy and Data, Not Politics and Ideology. Journal of Family Medicine and Health Care. Vol. 6, No. 1, 2020, pp.24-30. doi: 10.11648/j.jfmhc.20200601.15

Received: February 21, 2020; Accepted: March 9, 2020; Published: March 31, 2020

\begin{abstract}
Background U.S. healthcare spending will reach 20\% of GDP by 2026. Despite this spending, almost $14 \%$ of our under-65 population still lacks health insurance and out-of-pocket healthcare spending is high. To date, much of the healthcare reform debate has focused on who pays - the government, employers or individuals. Objective To review current healthcare reform issues and evidence. Method We address the questions of how much we pay, how we pay and what we receive for the money as a potential foundation for constructive dialogue. Results U.S. healthcare spending continues to exceed that of other countries, without offering universal coverage. Notwithstanding coverage expansions implemented under the Affordable Care Act, uninsurance rates have been rising. Rapid growth of high deductible plans has also significantly increased rates of underinsurance. There is very little evidence that specific policies or interventions employed to date will significantly reduce cost, especially under a fee for service system, where volume makes up for cuts. Global risk payments hold the greatest promise for real cost containment because they can drive true delivery system reform. Conclusion Meaningful, long-term healthcare reform cannot be successful until comprehensive, evidence-based policies that address healthcare costs are fully embraced and implemented.
\end{abstract}

Keywords: Healthcare Reform, Healthcare Cost, U.S. Healthcare System, Access and Coverage

\section{Introduction}

U.S. healthcare spending will reach $20 \%$ of GDP by 2026 [1]. Despite this spending, almost $14 \%$ of the U.S. under- 65 population still lack health insurance [2]. Because out-of-pocket costs for healthcare are high and continue to go up, an increasing number of insured Americans are having difficulty accessing comprehensive care. The plight of those who lack insurance (uninsured) and those who lack adequate insurance (underinsured) cannot be ignored.

To date, much of the healthcare reform debate in the U.S. has focused on who pays - the government, employers or individuals. Ultimately, the American people pay in one way or the other: through taxes, paycheck deductions, benefits in lieu of wages, or straight out of pocket. The real questions should not be who pays but should be how much can the
American public can afford to pay, how they pay and what they receive for the money. Healthcare reform will not be successful in the U.S. until comprehensive, evidence-based policies are fully embraced and implemented. The root causes of the American health system's problems must be clearly articulated, openly and publicly debated and addressed in order to develop a rational delivery model rather than one that just rations care.

\section{Skyrocketing Costs: Implications and Consequences}

In the U.S., the Medicaid program is funded jointly between state and federal governments to provide coverage for low-income populations. Medicaid accounted for $19.6 \%$ of 
spending from state general funds in 2016, more than doubling since $1990(9.6 \%)$ [3]. States that adopted Medicaid expansion under the Affordable Care Act (ACA) are particularly challenged since they now must cover the full $10 \%$ of expansion costs. Since most states cannot carry deficits from year to year because of balance budget requirements, they are forced to either raise more money (taxes) or cut spending somewhere else. This fiscal reality has forced state lawmakers to make some very painful decisions, and state-level healthcare reform may be the frontline in generating effective models for a restructured healthcare delivery system.

The U.S. federal government is not immune to the fiscal pain of high healthcare spending. The federal government spent nearly \$1.1 trillion on health care in fiscal year 2018 (27\% of the federal budget) [4]. Since employer and employee health insurance contributions are exempt from federal taxes, the government lost an additional $\$ 280$ billion per year in tax revenue. The U.S. federal deficit now exceeds a trillion dollars and is projected to grow; this level of spending will ultimately demand healthcare spending cuts.

Despite these massive financial commitments, the health status of Americans lags behind that of citizens in many other advanced countries, even though these countries spend substantially less on healthcare. For example, the U.S. ranks $24^{\text {th }}$ in infant mortality and $28^{\text {th }}$ in life expectancy at birth, falling behind most European countries [5]. Interestingly, countries with better health statistics tend to spend considerably more on social programs that address poverty and the social determinants of health (SDOHs), such as food security, housing adequacy, and education [6]. In fact, total spending on all social programs including healthcare is comparable between the U.S. and other countries with better health outcomes. Our spending approach just does not yield the bang for the buck in terms of health outcomes.

The impact of healthcare spending on the competitiveness of U.S. companies is also significant. Employer-sponsored (family) health insurance premiums rose more than 50\% between $2008(\$ 12,680)$ and $2018(\$ 19,616)$ [7]. Since employers currently pay about $72 \%$ of premiums, healthcare costs translate into reduced profits for U.S. companies. Warren Buffett described healthcare as "... a hungry tapeworm eating away at American companies" [8]. Many companies have responded by shifting healthcare costs to their employees. In 2018 , covered workers contributed, on average, $18 \%$ of the premium for single coverage and $29 \%$ for family coverage. Between 2006 and 2016, deductibles rose from an average of $\$ 303$ to over $\$ 1,200$. High deductible plans have become commonplace, covering $44 \%$ of adults ages 18-64 in 2017 and the percentage is projected to increase. Some companies, especially small (3-24 employees) and medium size firms (25-199), have simply stopped offering health insurance to their employees. In 2018 , only $57 \%$ of U.S. companies offered health insurance to their employees, down from a high of $69 \%$ in 2010. Many American companies have also shifted jobs outside the U.S. to take advantage of lower compensation costs, including low or zero healthcare costs.

Current healthcare costs also make healthcare unaffordable for millions of Americans and result in significant health disparities. In 2017, personal healthcare expenditures averaged $\$ 9,106$ per person in the U.S., or roughly $\$ 36,424$ for a family of four [9]. Comparing this amount to the U.S. federal poverty line [10] for this family size $(\$ 24,600)$ and the median household income $(\$ 61,400)$ for 2017 , the challenge becomes clear: most U.S. families cannot afford healthcare on their own. One in five working-age Americans with health insurance still reported problems paying medical bills in the past year, according to a Kaiser Family Foundation/New York Times survey [11]. Medical expenses have become a significant source of personal bankruptcy. Concerns over healthcare costs have become a middle-class issue and not just a problem of the poor.

Why does the U.S. spend so much money on healthcare? The most obvious culprit is the U.S. fee for service (FFS) payment system. There is simply no incentive to reduce utilization. In fact, quite the opposite: do more, get more. This incentive for volume can subliminally impact the behavior of even the most ethical, dedicated providers. The FFS payment system must be totally replaced by a reimbursement system that rewards efficiency and quality-value. A revised reimbursement system will drive the development of new delivery models that ensure access to high value care, focused on improving and preserving health and discouraging low-value care.

Part of the American over-utilization also stems from cultural attitudes and patient demand for access and choice engendered by the era of indemnity coverage when insurance paid for almost all services regardless of price and known efficacy. Many view unfettered access to healthcare as a right and reject the concept that healthcare is a critical public commodity that must be effectively and efficiently managed for the benefit of all. Until recently, U.S. insurance plans offered low copays, deductibles and out-of-pocket maximums, giving patients little financial incentive to curb unfettered use. Politicians have either directly or indirectly reinforced the demand for choice. During the debate about Obamacare, both parties promised that "no one should get between you and your doctor".

But some experts say that the U.S. spending on healthcare is a lot less about volume and waste and a lot more about prices. In a 2003 Health Affairs article, a group of economists showed that, aside from a few high-tech services, Americans actually use less healthcare than residents of other industrialized countries: fewer hospital days and fewer physician office visits [12]. U.S. high healthcare spending is actually the result of much higher prices. For example, a recent study from Kaiser Family Foundation found that the average price of an angioplasty was $\$ 31,620$ in the U.S.--far higher than Australia $(\$ 11,164)$, Switzerland $(\$ 10,066)$ or the U.K. $(\$ 7,264)[13]$. Similarly, C-section deliveries cost an average of $\$ 16,106$ in the U.S., compared to $\$ 9,965$ in Switzerland and $\$ 7,901$ in Australia.

The bottom line is that U.S. healthcare costs continue to spiral out of control. The rapid growth of high deductible and catastrophic plans means that individuals with insurance pay 
more out of pocket for less comprehensive coverage, potentially adversely impacting their health and healthcare. Measures of the health of the U.S. population lag behind other developed countries who spend less on healthcare but more on social programs that address poverty and SDOHs. It is hard to imagine that the U.S. can begin to address the critical issues of health disparities, underlying SDOHs, and universal coverage without reining in healthcare costs.

\section{What We Have Learned About Healthcare Cost Containment}

Historically, healthcare payers and policies have targeted healthcare prices by using standardized fee schedules, limiting price growth rates, and encouraging use of cheaper goods (e.g. generic medications) and services (physician office rather than emergency room). The results have been disappointing. In 1992, Medicare changed physician payments from a percent of billed charges to standardized fee schedules based on expected resources used. In subsequent years (1993-98), while fees remained relatively controlled, volume and intensity of physician services increased more than $30 \%$, resulting in an overall increase in spending for physician services [14]. In 1997, the Balanced Budget Act (BBA) established a sustainable growth rate (SGR) which tied increases in total physician payments to real, per-capita gross domestic product (GDP). This global budget cap was ultimately unsuccessful when the U.S. Congress repeatedly delayed implementation of necessary cuts to physician payments, and ultimately ditched the program because of immense political pressure from providers. Simply put, price controls in the U.S. have not worked.

\subsection{Prescription Drugs}

Americans spent an estimated $\$ 360$ billion on prescription drugs in 2019 (about $9.5 \%$ of all healthcare expenditures), and these costs are projected to grow at a rate of $4-6 \%$ per year for the foreseeable future [15]. To control costs, most payers strongly incentivize patients to select generics or accept therapeutic substitution (using chemically different drugs with same expected clinical effect). While generic and therapeutic substitution target drug prices, they do not address overall drug utilization. The recent onslaught of direct-to-consumer marketing of expensive pharmaceuticals and biologicals will tend to countermand and offset price control efforts. Even if the U.S. could bring prescription drug spending in line with Canada (about a 30\% reduction in per capita drug spending- a daunting challenge), this would only reduce national health expenditures by about 3\% [16]. Reducing spending on pharmaceuticals and biologicals, which has received much attention in the U.S. Congress, is an important incremental step but does not solve the U.S. healthcare cost problem. Viewing drug costs as a critical tool to support population health should force providers to use them judiciously, relying on evidence-based formularies, alongside disease management protocols and pathways where available.

\subsection{Administrative Simplification}

Administrative simplification has been espoused by many as a cost saving opportunity. The estimated annual cost to U.S. physician practices for interacting with health plans is $\$ 31$ billion or about $14 \%$ of total collections [17]. Hospital administrative costs accounted for $25 \%$ of U.S. hospital expenditures ( $\$ 215$ billion in 2011), far higher than any other country [18]. In addition, average insurer administrative costs are estimated at $12.4 \%$ of premiums [19]. Unfortunately, there is limited evidence that simplification efforts implemented in recent rounds of U.S. healthcare reform have reduced administrative costs [20]. On the contrary, some recent cost containment efforts have actually increased the complexity and costs of gathering and reporting of appropriate data. FFS payment creates an enormous amount of administration that will remain until we move to simplified payment models (i.e. full risk) and metrics that matter.

\subsection{Healthcare Fraud and Abuse}

Healthcare fraud is knowingly deceiving someone or misrepresenting information in order to receive payment, while abuse involves provision of services that are inconsistent with accepted medical, business or fiscal practices. The National Health Care Anti-Fraud Association estimates that health care fraud and abuse costs the U.S. $3-10 \%$ of its' healthcare spending (\$68 - \$230 billion annually) [21]. Under the ACA, the U.S. federal government significantly ramped up their fraud and abuse operations, collecting about $\$ 2.4$ billion in health care fraud judgments and settlements in 2017. While this is a substantial number, it still represents a very small fraction $(0.3 \%)$ of current Medicare spending (\$706 billion in 2017). Having a reimbursement system that does not reward volume, will go a long way in minimizing fraud and abuse.

\subsection{Medical Malpractice}

Medical malpractice in the U.S., including settlements, legal and administrative costs and defensive medicine, costs between $\$ 55.6$ - \$200 billion annually $(2.4 \%-10 \%$ of health spending). Ample evidence also indicates that the U.S. tort system does not compensate all patients equitably, [22] rapidly or efficiently [23] and may hamper efforts to improve patient safety [24] and lead to unnecessary tests and procedures [25]. To date, the data suggests that tort reforms have had an extremely limited impact on medical malpractice payments and overall healthcare costs [26].

\subsection{Provider Risk}

Shifting risk to providers has shown some promise for cost control. In the 1980s Health Maintenance Organizations (HMOs) used restricted provider panels, capitated payments (per member per month), and organized care protocols for cost control. Subsequently, HMOs lost popularity and became less effective in their cost containment efforts for two reasons. First, primary care physicians with responsibility for 
managing a patient's overall care were initially referred to as "gatekeepers" rather than "patient advocates". This very unfortunate label reinforced the lingering public concern that HMOs were focused on limiting choice and services to save money, rather than providing effective, cost efficient and comprehensive care. Second, state and federal courts undercut HMO cost control through a series of rulings, forcing them to pay for member use of non-HMO providers (see, for example, Moran v. Rush Prudential HMO). Even more devastating was the U.S. Supreme Court decision to uphold "any willing provider laws", reinforcing the entitlement mentality of enrollees.

In today's U.S. marketplace, payers have moved beyond simple capitation, to a system that combines global payments with financial incentives for patient access, quality of care, and health outcomes. In addition, use of better data systems and risk-adjustment models to account for the health of covered lives arguably generates more equitable payments than those in the 1980s and 1990s. The overall cost savings that can be expected with full-risk global payment systems is still unknown. An evaluation of capitated Medicaid managed care programs noted cost savings ranging from $2-19 \%$ compared to Medicaid FFS, mainly due to reduced inpatient care [27]. Research recently published in the New England Journal of Medicine demonstrated that global budget contracts with quality incentives can ultimately drive significant cost savings $(5.9-9.1 \%$ of average costs $)$ and quality improvement, but gains may take several years to be realized [28].

Because many providers are too small to assume substantial financial risk, Medicare has pursued more limited pay for performance (P4P) programs. Hospitals currently pay substantial penalties for hospital acquired conditions (HACs) and unplanned readmissions under Medicare's hospital P4P programs (close to $\$ 1$ billion in 2017). Physicians also face financial incentives to improve quality and lower costs under the Medicare Access and CHIP Reauthorization Act of 2015 (MACRA) [29]. Unfortunately, P4P imposes modest revenue decreases that can generally be offset by increased volume and 'careful coding'. Arguably, with full alignment of incentives, providers can be more engaged in meaningfully addressing quality and cost.

\subsection{Larger Risk Pools}

Larger risk pools create efficiencies and share risk among a larger group of beneficiaries. Authors of the ACA recognized that risk pooling could provide significant cost savings, mandating state-level health insurance exchanges to pool risk. To prevent adverse selection, where only the sickest enrollees end up in the pool, the ACA also included an individual mandate, requiring everyone to carry health insurance. Eliminating the individual mandate jeopardizes the ability of exchanges to control premiums. While many argue that it is unfair to require Americans to purchase health insurance, car insurance is compulsory in most states [30], and we would argue that most who don't purchase health insurance are counting on someone else (e.g. hospitals and/or Medicaid) to pick up the bill if they have a significant health crisis or illness, requiring expensive care.

Examining the range of strategies available to federal and state policymakers, we see very little evidence that specific policies or interventions will significantly reduce cost, especially under our FFS system, where volume makes up for cuts. Global risk payments hold the greatest promise for real cost containment because they can drive true delivery system reform.

\section{Health Insurance Coverage Is Moving in the Wrong Direction}

Recent attempts to control healthcare insurance costs have resulted in the rapid proliferation of high deductible health plans (HDHPs) and the introduction of "skinny plans", shifting risk to consumers and leaving an increasing number of insured Americans financially vulnerable. In addition, even after the ACA, $13.7 \%$ of adults still lack health insurance (Q4 2018), and these numbers are once again climbing. The rapid growth of the underinsured and the recent uptick in the uninsured is alarming many and has led to the "Medicare for All" movement.

\subsection{Underinsurance and Uninsured}

Since 2007, enrollment in high-deductible health plans (HDHPs) among employed adults age 18-64 has skyrocketed (from 5\% to $30 \%$ ) and continues to rise [31]. HDHPs are popular because their premiums are much lower than traditional plans, but that 'affordability' is driven by limited ("narrow") provider networks and high deductibles (e.g. \$2000 - \$5000/year).

HDHPs seek to engage individuals and make them smart consumers. As demonstrated by the classic Rand Health Insurance Experiment study, however, individuals with high out-of-pocket costs are likely to forego high value care that improves and preserves health, not just discretionary low value services [32]. High deductibles may also be a significant challenge for low-income individuals. So - most of the millions of low-income Americans who gain coverage through the ACA marketplaces are part of the growing underinsured population in our country, placing them at risk for foregoing necessary medical care or facing medical bankruptcy. Individuals with chronic conditions, even those with higher incomes, may also forego important medications and healthcare prior to meeting their deductible making this a middle class (and above) issue.

HDHPs also raise concerns about the wisdom of placing so much decision-making responsibility on patients. Enrollees are bombarded with data profiling provider costs and quality and offering diagnostic and therapeutic options. A recent comparison of hospital ratings from four different sources found that only $10 \%$ of the 844 hospitals rated as high performers by one rating system were rated as a high performer by the other rating systems [33]. It is little wonder that consumers find it difficult to incorporate these data in 
their decision-making.

\subsection{Uninsured}

While the ACA dramatically increased coverage between 2010 and 2017, many individuals still lack health insurance, and uninsurance is once again on the rise [2]. The Supreme Court's decision to allow states to opt out of Medicaid (2012) and the Trump Administration's decision to offer a wide range of exemptions from individual mandate penalties (2018) and lowering penalties to $\$ 0$ (2019) have weakened the impact of the ACA on coverage.

Presently there are 37 million uninsured in the U.S. and increasing [34]. Most are U.S. citizens (80\%), from childless households $(66.6 \%)$, between the ages of 18 and $49(64.5 \%)$ and working (82.4\%). Many have incomes below 200\% of the federal poverty line (57\%) and reside in states that did not expanded Medicaid (50.8\%). About 25\% of the currently uninsured are eligible for Medicaid, and another $10.4 \%$ are eligible for a marketplace plan with generous subsidies. This means many uninsured have not "opted in" for various reasons and should be targeted. Better Medicaid recruitment and retention methods could substantially increase coverage rates. It is also likely that additional states participating in Medicaid expansion will also have a beneficial impact on coverage rates.

\section{Principles That Should Define a Future Healthcare System}

Clearly the U.S. healthcare system is faltering. The cost of healthcare as a percentage of GDP continues to increase. U.S. healthcare costs are unsustainable. At the same time the number of uninsured and underinsured are substantial and rising. The debate over U.S. healthcare reform has been too narrow and predominantly driven by politics and ideology. It needs to be expanded, focusing on the questions of how much Americans pay (and can afford), how they pay (to drive change) and what they get. From our review of policy and data we have defined ten principles that should govern comprehensive reform of the U.S. healthcare system.

Principle 1. Universal or near-universal coverage. The cry for "Medicare for All" is really about increasing concerns over access to comprehensive and affordable care, rather than Medicare itself. This is as much about the underinsured as it is about the uninsured.

Universal coverage will certainly rectify our moral dilemma about healthcare being a human right. Expanding the risk pool will also potentially moderate rate increases for purchasers of insurance.

Principle 2. Comprehensive coverage of high value care. Access to and coverage of high value care, which improves and preserves health must be available to all. This can be achieved and facilitated through a standard benefit package, with modest deductibles and co-pays. Excessive out-of-pocket costs that discourage use of high value care are counterproductive. Low income individuals and people with chronic illnesses should have their out-of-pocket costs minimized, subsidized or even waived.

Principle 3. Enhanced benefits purchased with post-tax dollars. Individuals should be able to, at their own expense using post tax dollars, purchase additional benefits beyond those offered in the standard benefit package. Some would argue that this leads to tiered healthcare. We would argue that the U.S. already has 4 tiers: uninsured, under-insured, adequately insured and luxuriously insured (growing segment of concierge medicine). We would prefer 2 tiers: adequately insured and those who wish to purchase even more benefits.

Principle 4. Provider and patient engagement and support. Without widespread support from both providers and patients, significant change will fail. Physicians must assume responsibility for and take pride in a delivery system that provides effective, affordable, and equitable healthcare. Appropriate reimbursement systems for Medicare, Medicaid and other government sponsored health insurance plans can be a potent mechanism for engaging physicians. Likewise, consumers must recognize that effective, affordable, equitable healthcare is a critical public commodity that must be managed for the benefit of all. Some choice, particularly choice of plan, must be preserved; however, unfettered access that reflects the entitlement of the indemnity era cannot be supported.

Principle 5. Global payments with appropriate risk adjustment are necessary. Our current fee-for-service system incentivizes 'do more, get more', rather than emphasizing what matters: outcomes, cost, and patient care experience. Global payments, by shifting risk to plans and providers, encourages innovation and should catalyze changes in our healthcare delivery model, focusing efforts on efficiency, quality and satisfaction. One way that global budgets can be achieved is through vouchers or per capita payments. Vouchers might be purchased by individuals who receive additional pay in lieu of healthcare benefits; employers might offer vouchers as a healthcare benefit; Medicare and Medicaid might be administered through a voucher system; and the federal government could subsidize vouchers for low income individuals. Vouchers must fully cover the basic benefit package (Principle \#2). To adequately compensate for variation in enrollee health, appropriate risk adjustment needs to be used. Risk adjusting global payments (vouchers) will level the playing field: discouraging providers and plans from cherry-picking patients associated with more generous premium margins (premium minus cost) and adequately compensating those who serve high-needs patients (such as those with challenging social determinants of health). A voucher system does not necessarily disrupt our current insurance system. Vouchers could be used to purchase coverage through insurance companies or purchase coverage directly from a provider system or network.

Principle 6. Provider incentives for efficient, effective and patient-centered care. Alternative payment models that not only offer global payments with appropriate risk adjustment, but also include direct incentives for quality, access and outcomes, can catalyze changes in our delivery system, pressing for value and minimizing nonproductive and futile 
care. These models of payment should also encourage providers to manage and minimize administrative costs and discourage fraud and abuse. Aggressive competition among providers based on quality, patient satisfaction and access is necessary and essential to assure consumers that providers are not skimping on care. Providers will understand and respond much better to clear and direct incentives rather than overwhelmingly burdensome regulations.

Principle 7. Healthcare system consolidation must be allowed and supported. Large integrated networks and systems can provide comprehensive, coordinated and integrated services, align incentives to drive efficiency, safety, quality and satisfaction, serve sufficient numbers to manage risk, and be geographically dispersed to offer easy access. Consolidation combined with quality and price competition, what Enthoven called managed competition [35], creates countervailing market power on both purchaser and supplier sides that can support cost control, improved health outcomes and patient-centered care. Such entities are not just theoretical. Kaiser-Permanente, Geisinger Health, and Intermountain Health, among others, serve large defined populations and have demonstrated that they can deliver value, quality and efficiency. The Department of Justice is often opposed to consolidation because of presumed impact on prices. It may be true that consolidation under FFS often results in increased prices; this is not necessarily the case with global payments.

Principle 8. Clear information and consumer choice. Consumers should be offered clear, concise and easily understandable data, along with incentives that encourage sound choice among competing plans, based on quality, accessibility and satisfaction. In addition, performance measures should be adequately adjusted for patient complexity, so that consumers can make fair comparisons of providers. State and Federal governments can and should impose some licensing requirements on plans and require timely reporting of consumer-centric information.

Principle 9. Investment in evidence-based health system innovation. We need to know more about what works and does not work in our health system both clinically and organizationally. We spend a tremendous amount of money to develop treatments and programs, but relatively little to understand their dissemination, implementation and impact in the populations we serve. We desperately need to develop strong evidence on what works and use that evidence to drive further innovation.

Principle 10. Responsible and realistic cost control. Global budgets can bend the cost curve effectively, but this must be done gradually enough to avoid major disruptions to access and quality of care. Providers need time to construct and mature appropriate information systems and delivery models. We need to set an acceptable, achievable target for healthcare expenditures as a percentage of GDP and a timeline for achieving this cost control that is not pushed off course by special interest lobbying efforts. Reaching this target can free up much-needed dollars for other investments; federal and state governments will be able to fund other high-priority projects like education and infrastructure, while employers can re-invest in their companies and/or their employees to enhance their competitive positions. Most importantly, if healthcare costs are sufficiently reined in, we as a country can put more focus on health and the Social Determinants of Health and not just healthcare.

\section{Conclusions}

None of the principles we outline are new and unique. Together, however, they provide strategic direction for the changes our healthcare delivery system desperately needs. Not adhering to these principles will doom reform efforts. We must understand and accept that our healthcare system is deteriorating, and incremental change will not suffice. Comprehensive change will be difficult and incur opposition. As a nation, we must muster the political courage to get the job done. The cost of inaction is too high.

\section{References}

[1] Sisko AM, Keehan SP, Poisal JA, Cuckler GA, Smith SD, Madison AJ, et al. National Health Expenditure Projections, 2018-27: Economic And Demographic Trends Drive Spending And Enrollment Growth. Health Affairs. 2019; 38 (3): 491-501.

[2] Witters D. U.S. Uninsured Rate Rises to Four-Year High Washington DC: Gallup; 2019 [Available from: https://news.gallup.com/poll/246134/uninsured-rate-rises-four -year-high.aspx.

[3] Medicaid's Share of State Budgets. Medicaid and CHIP Payment and Access Commission; 2019.

[4] What are tax expenditures and how are they structured. The Tax Policy Center's Briefing Book a citizen's guide to the fascinating (though often complex) elements of the federal tax system: Tax Policy Center; 2019.

[5] OECD Data: Health [Internet]. 2020 [cited 01/15/2020]. Available from: http://www.oecd.org/health/.

[6] Bradley EH, Elkins BR, Herrin J, Elbel B. Health and social services expenditures: associations with health outcomes. BMJ Qual saf. 2011; 20 (10): 826-31.

[7] Claxton G, Rae M, Long M, Damico A, Whitmore H. The Kaiser Family Foundation Employer Health Benefits 2018 Annual Survey. 3 October 2018. 2018.

[8] Chappell B, Dwyer C. Amazon, Berkshire Hathaway and JPMorgan Chase Launch New Health Care Company [Internet]: National Public Radio; 2018 January 30, 2018. Podcast.

[9] National Health Expenditure Data Baltimore, MD: Centers for Medicare \& Medicaid Services; 2018 [updated April 17, 2018. Available from:

https://www.cms.gov/Research-Statistics-Data-and-Systems/Stati stics-Trends-and-Reports/NationalHealthExpendData/index.html.

[10] Health UDo, Human Services \%J Washington DUDoH, Services H. The poverty guidelines updated periodically in the Federal Register. 2015; 42.

[11] Hamel L, Norton M, Pollitz K, Levitt L, Claxton G, Brodie MJKFF. The Burden of Medical Debt: Results from the Kaiser Family Foundation/New York Times Medical Bills Survey. 2016. 
[12] Anderson GF, Reinhardt UE, Hussey PS, Petrosyan V. It's The Prices, Stupid: Why The United States Is So Different From Other Countries. Health Affairs. 2003; 22 (3): 89-105.

[13] Kamal R, Cox C. How do healthcare prices and use in the U.S. compare to other countries: Kaiser Family Foundation; 2018.

[14] Buntin MJ, Escarcé JJ, Goldman D, Kan H, Laugesen MJ, Shekelle P. Increased Medicare expenditures for physicians' services: what are the causes? INQUIRY: The Journal of Health Care Organization, Provision, and Financing. 2004 Feb; 41 (1): 83-94.

[15] Schumock GT, Stubbings J, Hoffman JM, Wiest MD, Suda KJ, Rim MH, Tadrous M, Tichy EM, Cuellar S, Clark JS, Matusiak LM. National trends in prescription drug expenditures and projections for 2019. American Journal of Health-System Pharmacy. 2019 Aug 1; 76 (15): 1105-21.

[16] Sarnak DO, Squires D, Kuzmak G, Bishop S. Paying for Prescription Drugs Around the World: Why is the U.S. an Outlier? Issue Brief (Commonw Fund). 2017; 2017: 1-14.

[17] Casalino LP, Nicholson S, Gans DN, Hammons T, Morra D, Karrison T, et al. What Does It Cost Physician Practices To Interact With Health Insurance Plans? A new way of looking at administrative costs - one key point of comparison in debating public and private health reform approaches. Health Affairs 2009; 28 (Suppl1): w533-w43.

[18] Himmelstein DU, Jun M, Busse R, Chevreul K, Geissler A, Jeurissen $\mathrm{P}$, et al. A comparison of hospital administrative costs in eight nations: U.S. costs exceed all others by far. Health Affairs 2014; 33 (9): 1586-94.

[19] Woolhandler S, Himmelstein DUJAoim. Single-payer reform: the only way to fulfill the president's pledge of more coverage, better benefits, and lower costs. Annals of Internal Medicine 2017; 166 (8): 587-8.

[20] Health Cost Containment and Efficiencies. Denver, Colorado; 2010.

[21] Association. NHA-F. The Challenge of Health Care Fraud. 2013 [Available from: https://www.nhcaa.org/resources/health-care-anti-fraud-resour ces/the-challenge-of-health-care-fraud.aspx.

[22] Brennan TA, Leape LL, Laird NM, Hebert L, Localio AR, Lawthers AG, et al. Incidence of adverse events and negligence in hospitalized patients: results of the Harvard Medical Practice Study I. New England Journal of Medicine. 1991; 324 (6): 370-6.
[23] Danzon PM, Lillard LA. Settlement out of Court: The Disposition of Medical Malpractice Claims. The Journal of Legal Studies 1983; 12 (2): 345-77.

[24] Gostin L. A Public Health Approach to Reducing ErrorMedical Malpractice as a Barrier. JAMA. 2000; 283 (13): 1742-3.

[25] Studdert DM, Mello MM, Sage WM, DesRoches CM, Peugh J, Zapert K, et al. Defensive Medicine Among High-Risk Specialist Physicians in a Volatile Malpractice Environment. JAMA. 2005; 293 (21): 2609-17.

[26] Waters TM, Budetti PP, Claxton G, Lundy JP. Impact of state tort reforms on physician malpractice payments. Health Affairs 2007; 26 (2): 500-9.

[27] The Lewin Group. Medicaid Managed Care Cost Savings-A Synthesis of 24 Studies. 2004.

[28] Song Z, Rose S, Safran DG, Landon BE, Day MP, Chernew ME. Changes in Health Care Spending and Quality 4 Years into Global Payment. New England Journal of Medicine. 2014; 371 (18): 1704-14.

[29] "Implementing MACRA, " Health Affairs Health Policy Brief, 2017.

[30] Araujo M. Understanding Minimum Car Insurance Requirements State-By-State List of Minimum Car Insurance Requirements: The Balance; 2019 [Available from: https://www.thebalance.com/understanding-minimum-car-insu rance-requirements-2645473.

[31] Claxton G, Rae M, Damico A, Young G, McDermott D, Whitmore H. Health Benefits In 2019: Premiums Inch Higher, Employers Respond To Federal Policy. Health Affairs. 2019; 38 (10): 1752-61.

[32] Brook RH, Ware JE, Rogers WH, Keeler EB, Davies AR, Donald CA, et al. Does Free Care Improve Adults' Health? New England Journal of Medicine. 1983; 309 (23): 1426-34.

[33] Austin JM, Jha AK, Romano PS, Singer SJ, Vogus TJ, Wachter RM, et al. National hospital ratings systems share few common scores and may generate confusion instead of clarity. Health Affairs. 2015; 34 (3): 423-30.

[34] Blumberg L, Holahan J, Karpman M, Elmendorf C. Characteristics of the Remaining Uninsured: An Update. The Urban Institute; 2018 July.

[35] Enthoven AC. The History and Principles of Managed Competition. Health affairs. 1993; 12 (suppl 1): 24-48. 